\title{
Colonialidad, Modernidad y representación en el cine latinoamericano contemporáneo. De Memorias del subdesarrollo a Pizza, Birra, Faso
}

\author{
Coloniality, Modernity and Representations in \\ Today's Latin American Cinema: From Memories Of \\ Underdevelopment To Pizza, Beer, Fag
}

\author{
Claudio Salinas \\ Universidad de Chile, Chile \\ claudiorsm@yahoo.com
}

Resumen • El artículo pretende revisar y analizar las maneras en que la colonialidad y las modernidades en América Latina han sido representadas, construidas y problematizadas en dos películas importantes para la cinematografía latinoamericana contemporánea: Memorias del Subdesarrollo (Cuba, 1968) y Pizza, Birra, Faso (Argentina, 1998). Dos son las preguntas que articulan el texto: ¿Qué imágenes de la colonialidad y la modernidad se despliegan en estas películas? ¿Cómo se articulan colonialidad y modernidad en las piezas visuales seleccionadas?

Palabras clave: Cine latinoamericano, Colonialidad, Modernidad

Abstract - The following paper aims to review and analyze how Latin America's colonialism and modernity have been represented, built and interrogated in two major films of regional contemporary cinema: Memorias del Subdesarrollo (Memories of Underdevelopment) Cuba, 1968 and Pizza, Birra, Faso (Pizza, Beer, Fag), Argentina, 1998. We have two questions to answer: What images of coloniality and modernity are pictured in these films? How are "coloniality» and «modernity» articulated in the selected films?

Keywords: Latin American cinema, Colonialism, Modernity 
Dos filmes hechos en Latinoamérica en dos "cines nacionales» ${ }^{1}$ distintos. Dos películas situadas en distintos contextos de producción material. La primera, Memorias del Subdesarrollo (Tomás Gutiérrez Alea, 1968, Cuba) filmada en la Cuba posrevolucionaria en un marco que la historiografía ha rotulado como «El Nuevo Cine Latinoamericano». La segunda, Pizza, Birra, Faso (Adrián Caetano, 1997, Argentina), rodada en el Gran Buenos Aires a fines del siglo pasado cuando la crisis asiática anunciaba el descalabro económico en Argentina. Ambas películas operando como vehículo de la representación, como un lugar de producción discursiva y simbólica respecto de nuestros países, a la manera de una construcción que propone regímenes de verosimilitud que evidencian, por cierto, la heterogeneidad estructural de la categoría «América Latina». Y aquí heterogeneidad estructural implica comprender América Latina en toda su variabilidad geográfica, política, cultural y económica. En este mismo sentido, Memorias del Subdesarrollo y Pizza, Birra, Faso operan sobre la realidad proponiendo maneras plurales en que los sujetos «experimentan» (Berman, 2010) la modernidad, construyen sus identidades y padecen la colonialidad del poder y del ser, como una cuestión siempre vigente, siempre actualizada, siempre presente.

Para aceptar este marco debemos entender que «un filme no es una ilustración o una confesión, es ante todo un objeto, fruto de un trabajo» (Casetti, 244). Si el cine es construcción, entonces estamos ante un dispositivo que pone en escena algo, una realidad exterior o una vivencia - y ésta es también su condición estética-, pero no a la manera de un reflejo especular, sino por el contrario, un espacio en el que se despliegan conflictos que dan cuenta de la tensión permanente entre el sustituto (la imagen) y lo sustituido (la realidad). Lo que está en pugna, por tanto, es una perspectiva en que el cine, por medio de sus películas, entra a disputar la hegemonía de las representaciones simbólicas posibilitando la identificación de unos imaginarios sociales ${ }^{2}$ en que los

En este texto utilizamos la expresión «cines nacionales» para indicar y hacer explícitas las diferencias (contextos de producción) entre las distintas cinematografías latinoamericanas. No existe algo así como «el cine latinoamericano» único, sin particularidades locales. En esta diferenciación recogemos las perspectivas del historiador brasileño del cine Paulo Antonio Paranaguá, quien señala: «El cine latinoamericano no existe como plataforma de producción: el espacio donde se generan la casi totalidad de los proyectos es puramente nacional, a veces incluso local, pero hay corrientes transnacionales y estrategias continentales por lo menos desde el advenimiento del cine sonoro, sin hablar de antecedentes aún más remotos» (2003:15). Un enfoque similar lo provee John King en el ya clásico texto El carrete mágico. Una historia del cine latinoamericano (1994), quien utiliza la forma «cines nacionales» para referirse a las distintas vertientes y desarrollos cinematográficos que han tenido y tienen lugar en América Latina desde la época del cine mudo. No obstante, reconoce el deseo "panamericanista» de los cineastas de los '60, sobre todo, a partir del Festival de Cine de Viña del Mar de 1967, que congregó a los directores-intelectuales más representativos de los «nuevos cines» latinoamericanos como el brasileño Glauber Rocha o el cubano Santiago Álvarez, entre otros.

2 La noción de «imaginarios sociales» aquí empleada es consistente con la definición que Cornelius Castoriadis expone: «(...), este término comprende tanto las prácticas como las representaciones que se refieren a las identidades de los miembros de una comunidad sociopolítica; esto es, a los modos de pertenencia, normas comunes y aspiraciones, asignación de significado a acontecimientos que se consideran cruciales, y narrativas diversas» (Girola, 48). Los «imaginarios sociales» son los conocimientos implícitos sobre el sentido de la modernidad, lo que significa ser moderno y, por cierto, cristalizan en representaciones como, por ejemplo, las desplegadas y construidas masivamente por el cine (Girola, 48). Por esta razón, los imaginarios sociales se convierten en espacios de reconocimiento de la sociedad que, en tanto construcciones simbólicas, hacen posible las relaciones entre personas, objetos e imágenes». 
sujetos se reconocen $-\mathrm{y}$ reconocen a los otros- en el propio devenir de las relaciones de poder, en el propio devenir de la colonialidad y la modernidad en los países de América Latina ${ }^{3}$.

Para abordar las cintas mencionadas necesitamos particularizar aún más nuestra perspectiva comprensiva sobre el cine y sus películas: primero, es una tecnología de la comunicación. Y por tecnología de la comunicación utilizaremos la concepción que Raymond Williams desarrolla en Historia de la Comunicación:

Una técnica es una habilidad particular, o la aplicación de una habilidad (...). En contraste, una tecnología es, en primer lugar, el marco de conocimientos necesarios para el desarrollo de dichas habilidades y aplicaciones y, en segundo lugar, un marco de conocimientos y condiciones para la utilización y aplicación prácticas de una serie de ingenios (184).

En tanto tecnología de la comunicación, a nuestro entender, el cine se convierte en una forma cultural, en expresión de relaciones sociales. Pero no sólo de relaciones sociales: también es posible advertir las formas políticas, culturales, las epistemes, los discursos, los sujetos y sus relaciones de poder en una época determinada bajo condiciones específicas. El cine nos permite, por tanto, captar la o las «estructuras del sentir» (Williams, Marxismo y literatura) de periodos históricos, captar los procesos por sobre sus contingencias, sus fragmentos en relación a la totalidad social.

El cine deberá entenderse como un dispositivo que, en este caso, debe implicar «una red de relaciones entre cosas, hombres y prácticas sociales. No es una idea, sino una máquina. No es un objeto, sino un conjunto de ellos» (Salinas: 2). Por otra parte, el dispositivo, en términos foucaultianos es una disposición de todos estos elementos con un propósito: disciplinar los cuerpos, normalizar las existencias para configurar un orden del discurso, un orden de la representación de la realidad (Foucault en Deleuze, 155-163). ¿Cuál es la gravedad de esta comprensión? Desnaturalizar la realidad: cuestionar las maneras hegemónicas de entenderla, poner en suspenso, por de pronto, las comprensiones positivas de la modernidad y los procesos de modernización ${ }^{4}$ asociados e inscritos en colonialidades diversas.

Interesa para nuestros fines en este texto comprender a los medios de comunicación, y en especial el cine, no sólo como transmisores de contenidos o como meros soportes, sino agencias desde la cuales se piensan y construyen las sociedades modernas, aunque la teoría social tradicional piense que sólo son esferas de lo superficial y lo efímero. Como dice John Thompson en Los medios y la modernidad: «(...) una teoría social de los media podría ayudar a ubicar su estudio en un punto en el que, desde mi perspectiva, le pertenece: entre un grupo de disciplinas preocupadas por las emergencia, desarrollo y características estructurales de las sociedades modernas y sus futuros» (19-20). Y agrega, puntualizando el sentido de la comunicación y de los medios en la producción de la modernidad: «Trataré de demostrar que el desarrollo de los medios de comunicación - desde las primeras formas de impresión hasta los recientes tipos de comunicación electrónica-constituye una parte integral del surgimiento de las sociedades modernas. El desarrollo de los medios de comunicación se mezcló de manera compleja con un determinado número de procesos de desarrollo paralelos que, tomados conjuntamente, constituyeron lo que hemos convenido en llamar la «modernidad»» (Thompson, 15).

4 Aquí entenderemos por "procesos de modernización» a la operacionalizaciones particulares de la modernidad y la disputa por su carácter. Por modernización Marín y Morales entenderán a «(...) la operacionalización del proyecto de la modernidad, donde ciertas características [expansión de la educación, alto grado de urbanización, acceso a la electricidad, al alcantarillado, etc.] permitirían que una sociedad abandone los rasgos tradicionales para constituirse como una sociedad moderna» (6). Como veremos en el capítulo siguiente, si para «entrar y salir de la modernidad» existen distintas avenidas de sentido y multiplicidad de posibilidades y combinatorias en América Latina, las modernizaciones aparecerán, por tanto, como el terreno de lo disputable, como aquellos procesos que nos recuerdan las actuales visiones hegemónicas respecto a una determinada modernidad imaginada y proyectada. 
El cine como tecnología de la comunicación. El cine como un dispositivo que exhibe modos de experienciar las modernidades y las colonialidades. Los filmes, a su vez, materializando el dispositivo, tienen lugar dentro de lo que podríamos llamar el régimen de visualidad moderno (Zunzunegui, 2005). Este régimen o racionalidad implica disciplinar las miradas "para que aprendamos a ver su horizonte de una manera específica, como propuesta de sentido» (Salinas, 2). En nuestro caso, con las dos cintas seleccionadas: se trata de dos regímenes visuales distintos — dos disposiciones de la modernidad y la colonialidad-, pero relacionados: el primero, nos remite a la cinta de ficción cubana Memorias del Subdesarrollo, que pone en escena una racionalidad del tipo fordista/desarrollista en la posrevolución cubana, en la que en principio se despliegan unos sujetos y unas epistemes que constatan un tipo de modernidad, homogénea, con identidades psicologizadas (Rojo, 2005), en la que se evidencia su comprensión dualista, como diría Martín-Barbero en Los medios a las mediaciones (1998) o Renato Ortiz en Benjamin en París (2000). Como nos advierte el título: lo que está en juego es el «desarrollo» o el «subdesarrollo», la "civilización o la «barbarie» en un plan de transformación nacional hacia «la» modernidad.

En el segundo régimen, en el que podemos situar a Pizza, Birra, Faso, cinta también de ficción que materializa una racionalidad del tipo postfordista/postdesarrollista ${ }^{5}$ en la Argentina neoliberal de Carlos Menem, en la que, a priori, podemos decir que se exhibe un mundo en que la transformación nacional -y las identidades colectivas asociadas- ha dejado paso a la derrota del Estado-nación, a la aparición de «individuos» que amenazan la tranquilidad funcional de la polis del orden de la globalización y que, sobre todo, parecieran poner en tensión los discursos respecto a un tipo de identidades esenciales y monológicas. ¿Qué epistemes pone en juego? Lejos de exhibir un camino lineal, como comentan los autores representantes de los Estudios Subalternos Latinoamericanos (Quijano, 2007; CastroGómez, 2005; Mignolo, 2005), traslucen toda la incertidumbre y la precariedad económica del fin de siglo y, lo que es más importante, la necesidad comprensiva de entender una serie de mundos de "otro modo", por medio de otras sensibilidades, provistos de otros aparatajes, probablemente distintos a las estadísticas o a la categorización estática de las sociedades.

\section{COLONIALIDAD, MODERNIDAD}

¿Qué imágenes de la colonialidad y la modernidad se articulan o se exhiben en Memorias del subdesarrollo y Pizza, Birra, faso audiovisuales? Luego, ¿qué respuestas a este proceso despliegan los cineastas en estos filmes? Y ¿qué imaginarios de la modernidad se despliegan? ¿Qué tipo de comunidad se imaginan?' Por ahora, una idea de base: la

\footnotetext{
Santiago Castro-Gómez dice, basándose en las tesis de Negri y Hardt, que con el advenimiento del postfordismo el «capitalismo mundial entra en la última y definitiva fase de su historia; el Imperio. El tipo de economía no es ya la de los objetos, sino la de símbolos y lenguajes abstractos» (2005:68).

6 Benedict Anderson señala que la principal «comunidad imaginada» es la nación. La figura "comunidad imaginada» se sustenta en que «aun los miembros de la nación más pequeña no conocerán jamás a la mayoría de sus compatriotas, no los verán ni oirán siquiera hablar de ellos, pero en la mente de cada uno vive la imagen de su comunión» (23). Esto implicará que, pese a que estamos frente a una construcción simbólica, las consecuencias son evidentemente materiales, observables en los comportamientos de los sujetos incluidos dentro del colectivo imaginado. Colectivo que siempre concibe su identidad de manera relacional y aumentando las diferencias con otros grupos percibidos y categorizados como distintos.
} 
dimensión cognitiva o simbólica del colonialismo (Castro Gómez, 2005); es decir, la colonialidad no ha sido cancelada en nuestra época contemporánea. Es más, forma parte constitutiva y constituyente de la lógica colonial desde el siglo XVI hasta nuestros días. Claro que se ha expresado, organizado, construido y deconstruido de distintas maneras. Siendo objeto de distintas respuestas desde la academia y, en nuestro caso desde los discursos cinematográficos. ¿Qué podríamos entender por colonialidad, entonces? ¿Es distinta al término colonialismo? Al respecto dice Aníbal Quijano:

Colonialidad es un concepto diferente, aunque vinculado con el concepto de colonialismo. Este último se refiere estrictamente a una estructura de dominación y explotación, donde el control de la autoridad política, de los recursos de producción y del trabajo de una población determinada lo detenta otra de diferente identidad, y cuyas sedes centrales están, además, en otra jurisdicción territorial. Pero no siempre, ni necesariamente, implica relaciones racistas de poder [...] El colonialismo es, obviamente, más antiguo, en tanto que la colonialidad ha probado ser, en los últimos 500 años, más profunda y duradera que el colonialismo. Pero sin duda fue engendrada dentro de éste y, más aún, sin él no habría podido ser impuesta en la intersubjetividad del mundo, de modo tan enraizado y prolongado (93).

Colonialismo y colonialidad, dos ejes para nuestro análisis: mientras el colonialismo implica la dominación, de manera general, de un Estado sobre otro, la colonialidad también da cuenta del tipo de dominación que se da al interior de los países, periféricos y metropolitanos, por llamarlos de alguna manera. El concepto de colonialidad nos permite actualizar la comprensión de las relaciones coloniales y escamotear aquellas visiones que las declaran acabadas con la emancipación de las últimas naciones del Tercer Mundo, independizadas de sus metrópolis a mediados de los años 60.

La categoría colonialidad, comprendida tanto en su dimensión interna como externa, a la vez, se la puede asociar a ciertas demarcaciones sobre lo que podemos entender por modernidad. Decimos demarcaciones, porque cuando hablamos de la modernidad en este texto, asumimos una perspectiva de investigación que descentra una pretensión que le atribuye un origen y una autenticidad sólo europea y en que en el devenir de la historia sólo le quedarían a las otras regiones del planeta la posibilidad de la copia, la reproducción de un derrotero prefijado que debería seguirse en pos del acceso a la civilización (Cfr. Larraín, 1997, 2005).

Modernidad es un término polisémico con al menos cuatro sentidos: época, estructura institucional, experiencia vital, y discurso y proyecto civilizatorio. Lo importante radica en que ninguno de los cuatro usos agota sus sentidos, pero el término necesita ser analizado en esas cuatro dimensiones si se quiere confeccionar un retrato hablado de sus rasgos y pulsiones (Brunner, 174). ¿Cómo entender, entonces, el concepto de modernidad en nuestro continente? Para responder esta interrogante, suscribimos la noción de modernidades para enfatizar su heterogeneidad y su multiplicidad. Cuando hablamos de modernidad heterogénea, nos hacemos eco de la propuesta de Hermann Herlinghaus quien advierte que se trata de un "concepto de búsqueda», de observación de procesos en los cuales se constituyen tanto los sujetos, sus experiencias y sus identidades en Latinoamérica (773). En este mismo sentido, Brunner, citando a Jesús MartínBarbero en su célebre texto De los medios a las mediaciones, señala que la versión latinoamericana de la modernidad observada desde ciertos dispositivos de mediación como el mercado, la ciudad, la escuela y sobre todo los llamados medios de comunicación de 
masas, dan cuenta de una «experiencia de heterogeneidad cultural» (177). Lo que olvida el autor, sin embargo, es que esta heterogeneidad latinoamericana no sólo se exhibe respecto de Europa, sino también entre las naciones que conforman Latinoamérica. La modernidad es una y diversa, nos recuerda Renato Ortiz en Benjamin en París. Néstor García Canclini, a su vez, llamará a esta modernidad diversa, modernidad híbrida, aludiendo a que las vías latinoamericanas implican constantemente mezclas productivas, por ejemplo, entre lo foráneo y lo local o entre lo antiguo y lo nuevo (13-31). El hecho mismo de reflexionar sobre las modernidades múltiples es un indicador de modernidad (Brunner, 2002).

Pasaremos a revisar la asociación entre las concepciones de colonialidad y modernidad en dos películas relevantes para la cinematografía de nuestras latitudes: Memorias del Subdesarrollo y Pizza, Birra, Faso. ¿Qué método de acercamiento utilizaremos? ¿Cómo procederemos metodológicamente? A través del reconocimiento de cuatro dimensiones de análisis consistentes con lo enunciado por Raymond Williams en Sociología de la Cultura: la descripción de los sujetos y las subjetividades desplegadas en las cintas (en este caso se trata de ubicar cómo se construyen las identidades y su naturaleza); el reconocimiento de las epistemologías que estarían operando; los discursos desarrollados; las instituciones que aparecen representadas en las construcciones visuales. Todos estos ámbitos serán cruzados comparativamente en cada una de las cintas y entre ellas cuando corresponda.

\section{MEMORIAS DEL SUBDESARROLLO Y LA «RAZÓN DUALISTA»}

Un tipo de colonialidad y modernidad exhibida explícitamente, sin ambages y recorriendo todo el relato fílmico. Asistimos a la crisis terminal de un modelo de vida burgués. Su director, Tomás Gutiérrez Alea, escamoteando la caricatura del pequeño burgués, nos propone un personaje central, Sergio, un sujeto angustiado por la Revolución y por la imposibilidad de un modo de vida puramente individual en una ciudad, La Habana, que ya no le pertenece o que, mejor dicho, en la que vierte su malestar ${ }^{8}$. Se trata de una subjetividad burguesa que se queda en Cuba para ver y experienciar el proceso revolucionario, sus transformaciones, sus pérdidas. Él es un observador que pareciera ser que no encuentra su lugar o más bien que reconoce su incomodidad en la Cuba

\footnotetext{
Es una de las películas cubanas que sintetiza de manera más compleja y elaborada la reacción que, desde las cinematografías latinoamericanas, se produjo respecto a los países «imperialistas» (Estados Unidos, particularmente) y al colonialismo. Ha sido considerada como uno de los emblemas del movimiento conocido en los 60 como "Nuevo Cine Latinoamericano» y, además, es un título recurrente en cualquier compilación que pretenda seleccionar a los mejores y más representativos filmes de los cines nacionales latinoamericanos de los 60 (Ver Rufinelli, 2010; Stam, 2001).

8 Como bien señala Héctor Quiroz en el artículo El malestar por la ciudad contemporánea a través del cine, la percepción sobre una ciudad amenazante es un tópico característico de las narraciones y discursos presentes en distintas versiones de la modernidad. Y, en la construcción de estos relatos el cine, por su misma naturaleza, posee una capacidad excepcional para reconstruir el espacio y la temporalidad de la ciudad, «enriqueciendo con su particular enfoque la comprensión del fenómeno urbano contemporáneo» (Quiroz, 7). Respecto a la ciudad Latinoamericana, dice Quiroz: «Además del crecimiento espectacular, la ciudad latinoamericana contemporánea se caracteriza por ser el resultado de una doble realidad: por un lado el proyecto oficial, inspirado en la ideología del progreso y basado en la vanguardia tecnológica, y por otra, la ciudad construida de manera espontánea por millones de marginados» (Quiroz, 6).
} 
posrevolucionaria. ¿Qué es lo que acontece? La primera respuesta: el agotamiento de un imaginario social y la posibilidad de su reemplazo por otro que, sin embargo, debe «modernizarse». Y modernizarse significa sólo una cosa: que las «masas» de cubanos abandonen sus prácticas tradicionales y se despojen del «atraso mental» que sería su característica identitaria predominante.

El filme combina la ficción con el registro documental para entregar la mayor veracidad a la construcción cinematográfica, como reconoce su director en La dialéctica del espectador, texto publicado en 1978. Esta cinta, anclada en el Nuevo Cine Latinoamericano, podría dividirse en tres momentos: el primero, cuando Sergio va a dejar a sus padres y esposa al aeropuerto de La Habana con destino a Estados Unidos. Son sus parientes burgueses que abandonan el país para dirigirse al «Imperio», en 1961, meses antes de que se desencadenara la llamada «crisis de los misiles». El segundo: cuando Sergio conoce a la joven Elena, representante de los sectores populares de la Isla. Mantienen una relación, pero rápidamente el personaje central se aburre de la simpleza y, sobre todo, porque sujetos como la joven le recuerdan literalmente «el subdesarrollo». El tercero: Sergio es acusado por Elena y su familia, en tribunales, de engaño y falsa promesa de matrimonio. Sergio dice: «he visto demasiado para ser inocente, pero los demás están demasiado confundidos para ser culpables». Ciertamente una paradoja que da paso a los recuerdos de Sergio de su antigua novia Hanna, que se marchó a Nueva York, mientras él se enriquecía con la mueblería que su padre le obsequió. «El afán burgués de poseer le hizo perder lo <único bueno» que le pasó en la vida", dice el crítico uruguayo, Jorge Ruffinelli (86). De alguna manera, la película en general moviliza una «razón dualista»: o somos desarrollados en los términos «eurocéntricos» o somos subdesarrollados, atrasados, bárbaros.

De escoger el «subdesarrollo», lógicamente, cancelamos nuestra «única» posibilidad de ser modernos. Con este tipo de concepción del sentido de la modernidad, la colonialidad epistémica que se exhibe es una que, a su vez, se inscribe dentro de las mismas claves que le dan lugar. No hay un cambio de episteme en los discursos generales que se muestran en la película. Como si la nación cubana fuese «una», sin diversidad compositiva y relacional. ¿Cuál es la consecuencia? Concebir la identidad como si fuese una construcción monolítica, esencial, prístina. Una identidad que pareciese anteceder a los procesos de su producción en Cuba y, quizás por extensión, a las demás naciones latinoamericanas. Se trata de una psicologización ${ }^{9}$ y un emplazamiento de las identidades que implica una operación específica en el interior mismo de una Cuba que busca «la» modernidad:

Mientras es posible y legítimo hablar de una identidad personal en términos de «carácter〉o la <estructura psíquica de un individuo, no es adecuado hablar de una identidad colectiva en términos de un 〈carácter étnico〉 o de una 〈estructura psíquica colectiva〉 que sería compartida por todos los miembros de un grupo (Rojo, 31).

Esta psicologización de las identidades sería posible, a modo de hipótesis, porque la construcción de las identidades responde a una teorización respecto de lo que son los sujetos y lo que deben ser en términos colectivos. Distinto es el caso cuando lo que opera en la cinta es una producción de sujetos guiados por las necesidades dramáticas, razón por la cual y también, de manera muy preliminar y precaria, los personajes no simbolizan más que sus propias circunstancias o las de sus cercanos. 
De alguna manera, el planteamiento que nos propone vehiculiza identidades de reemplazo fijas para acceder a la modernidad. En este contexto, ¿qué institución permitirá en la cinta acceder a la modernidad? En el país del Caribe, será la Institución Revolución. Carlos Ossandón y Eduardo Santa Cruz, respecto a esta «razón», señalan que dicha perspectiva es común en las Ciencias Sociales, estando presentes también en los enfoques críticos de cuño marxista que contraponen, por ejemplo, lo culto a lo masivo, la homogeneización a la fragmentación o lo tradicional a lo moderno. Más interesante, dicen los autores, es ver al Estado-nación desde el contexto de la matriz moderna y no sólo siendo determinado por corrientes extranjeras, buscando los modos en que la modernidad aparece de forma particular y material en las distintas formaciones nacionales que componen la categoría América Latina. Por tanto, lo que existe serán los trayectos a la modernidad, una modernidad heterogénea que combina elementos de distintas densidades, de antiguas y nuevas formaciones sociales, o lo que podríamos denominar como lo tradicional con rasgos propios de las modernidades ${ }^{10}$. De esto se desprende la hipótesis de que existen distintas maneras de entrar y salir de la Modernidad, de leerla o relacionarse con ella. Por tanto discutir sobre si somos o no modernos sería una ejercicio estéril (1718). Respecto a la «razón dualista cartesiana» que opone al «desarrollo» el subdesarrollo, dice Santiago Castro-Gómez:

Durante las décadas de 1960 y 1970 los Estados nacionales —apoyados en el diagnóstico de las ciencias sociales, en particular de la economía- definieron el desarrollo de los países del Tercer Mundo por referencia a los indicadores de industrialización. Se suponía que el desarrollo económico dependía del desdoblamiento de la industria, de tal manera que el sub-desarrollo correspondía a una etapa histórica pre-industrial (78).

Pese a que en el filme las oposiciones binarias son marcadas, no podríamos hablar de personajes planos y de un lenguaje cinematográfico escaso en recursos. Esto se expresa, primero, en la ambigüedad de Sergio, quien "quiere vivir como europeo» en un país que ha dejado de ser «el París del Caribe» y se ha transformado en una «Tegucigalpa del Caribe». En segundo lugar, Sergio es un personaje ambiguo, contradictorio, pues aborrece a los burgueses que fueron la clase dominante - y al sector que perteneció o al que pertenece como un resabio- y a la vez se desprecia a sí mismo, aunque piense que es superior a todos (el problema eran las clases, finalmente) ${ }^{11}$. Las fisuras de la Cuba Revolucionaria se dejan ver por medio de las contradicciones de Sergio, cuya identidad se ha despedazado o está en proceso de serlo. El tiempo del cine se corresponde con la crisis de la identidad burguesa, forjada en tiempos del capitalismo internacional.

10 Respecto a la modernidad en sentido plural dice Renato Ortiz en Benjamin en París (2000): «La modernidad es una y diversa. Una, en cuanto matriz civilizadora; diversa, en su configuración histórica. Industrialización, urbanización, tecnología, racionalización son rastros que penetran todas las modernidades (...) Pero cada una de ellas se realiza de manera distinta de acuerdo a las condiciones históricas de cada lugar. En ese sentido ella es múltiple. Sabemos esto antes de cualquier discusión teórica refinada puesto que la historia de los países latinoamericanos subraya esa diferencialidad» (9).

11 Gutiérrez Alea dice del protagonista: «En un sentido, Sergio representa el ideal que cada hombre, con esa particular mentalidad (burguesa), desearía llegar a ser: rico, atractivo, inteligente y con acceso a los estratos altos de la sociedad y a hermosas mujeres que desean acostarse con él como personaje. Las películas juegan con esta identificación. (...) Pero, ¿qué ocurre después? A medida que se desarrolla la película uno empieza a percibir no sólo la visión que tiene Sergio de sí mismo, sino también la visión que de la realidad tenemos nosotros, los realizadores del filme. La película corresponde a nuestra visión de la realidad y también a nuestra visión crítica del protagonista» (Paranaguá, 222-223). 
¿Cómo se expresan estas complejidades? Por medio de un montaje dialéctico en el que se empalmen planos y tomas que asemejan un «choque de ideas», como diría el cineasta y teórico soviético Sergei Einsenstein, en los años 20 del siglo pasado (por ejemplo un primer plano de un rostro y una imagen siguiente de un carnaval, en nuestro caso). Este tipo de montaje produce una síntesis que corresponde a un concepto. De la misma manera se intercalan imágenes de noticieros que transmiten una entrevista con los participantes de Playa Girón o con las informaciones que dan cuenta de la gravedad de la «Crisis de los Misiles». Se trata de introducir veracidad al relato fílmico por medio de un lenguaje que introduzca el proceso de deconstrucción de las identidades de los personajes en unos decorados lo más fieles a la «realidad real». Una puesta en escena verista, podríamos concluir. El mismo Gutiérrez Alea señala: «Las imágenes documentales contribuyen a ubicar el conflicto en su marco social e histórico» (97).

Pero no sólo el tratamiento cinematográfico de los discursos sobre la identidad vuelve compleja esta película, sino también algunas alusiones textuales al «afuera» revolucionario y a su futuro. Esto ocurre promediando la cinta cuando Sergio asiste a una mesa redonda en la Casa de las Américas, lugar donde exponían intelectuales como David Viñas y Edmundo Desnoes, entre otros, que son interpelados por la pregunta de un estadounidense desde la audiencia: «Si la revolución cubana era tan radical en todos sus órdenes, por qué los intelectuales continuaban discusiones redundantes y obsoletas en vez de buscar nuevos modos de comunicación». Con esta secuencia se aprecian de manera clara las preocupaciones de nuestro cineasta-teórico Tomás Gutiérrez Alea, quien en 1968 , fecha en la que se estrena la película, estaba preocupado por los destinos de la Revolución, por su institucionalización y su proyección en el tiempo, de manera sociológica, prospectiva $^{12}$. No podía ser de otro modo, eran los aires transformacionales de la época, la que se caracterizaba por pensar la manera en que se podía enfrentar permanentemente al «Imperio», es decir Estados Unidos. Probablemente la idea es «reinventar» América Latina desde la imagen de la colonialidad misma, pero aún «empapados» de su episteme territorializadora, en el marco de su propia lógica.

El mismo cineasta reconoce la complejidad fílmica y discursiva de la película, como si se tratase de una intención manifiesta y de un universo cinematográfico totalmente controlado: se trataba de no esquematizar la realidad en aras «de una pretendida exaltación de los valores revolucionarios, pues un cine militante desde dentro de la revolución no es nada sencillo ${ }^{13}$. El cine debe ser movilizador y que estimule la participación en el proceso revolucionario» (Gutiérrez Alea: 98). El cine sirviendo a la pedagogía de las masas,

12 John King en El carrete mágico señala: «La función del intelectual en la Revolución había estado en la agenda a lo largo de los años sesenta. La exploración más interesante del problema en cualquier medio cultural se encuentra en Memorias del subdesarrollo (1968), de Gutiérrez Alea, basada en una novela de Edmundo Dasnoes» (222). ¿Cuál sería esa función? Ciertamente lo que se requería en un contexto posrevolucionario era la «transición, en términos de Gramsci, del intelectual tradicional al intelectual orgánico, reconociendo la necesidad de compañeros de viaje, pero también admitiendo que esos compañeros debían comprometerse en el largo plazo» (217).

13 Dice King, en relación a la complejidad discursiva que exhibe Memorias del subdesarrollo respecto a la Institución Revolución cubana: «Memorias apoya este proceso de movilización, pero no de una manera maniquea. Muestra que la Revolución no está conformada por nuevos hombres y mujeres estereotipados y ejemplares (el sueño del Che Guevara aún estaba lejos de alcanzarse), sino de individuos todavía afectados por deseos y aspiraciones contradictorios. Esto hace más eficaz el resultado final de la película» (224). 
pero no infantilizándolas, por el contrario, haciéndolas participar de las políticas de la interpretación.

¿Cuál es el límite de Memorias del Subdesarrollo? El límite es su respuesta y su época: su construcción discursiva se apega, aunque con mayor complejidad y menos maniqueísmo que otras cintas de la época como La Hora de los Hornos (Solanas y Getino, Argentina) ${ }^{14}$, a los relatos anticoloniales, a su lógica que discute en los mismos términos — pero invertidos - la colonialidad y la modernidad. Al respecto dice Restrepo:

El grueso de las críticas al colonialismo de mediados del siglo xx establecía una relación de exterioridad entre lo epistémico y el colonialismo, mientras que las diferentes vertientes de las discusiones poscoloniales evidencian, precisamente, cómo lo epistémico y lo colonial se constituyen e influyen mutuamente (Restrepo en Castro-Gómez y Grosfoguel, 291).

No nos olvidemos que estamos en presencia, de manera general, de narrativas anticoloniales, marcadas, como dice Stam, por el «discurso nacionalista» de cineastas-intelectuales «que se sienten obligados a hablar en nombre de toda la nación y sobre los temas que acucian a ésta» (329). Estamos en un período en el cual se intenta dejar de impostar la voz de lo foráneo, de lo «eurocéntrico». Al respecto dice Dussel: «Para descubrir nuevas categorías con las cuales nos sea posible pensarnos a nosotros mismos hay que comenzar por hablar como los europeos y, desde ellos, probar sus limitaciones, destruir el pensamiento europeo para dar lugar a uno nuevo» (cit. en Castro-Gómez, 44).

Pero el probar las limitaciones de la episteme de «una modernidad» única, excluyente onmiabarcadora, homogénea y homogeneizante, será tarea de la siguiente película a analizar. De antemano, eso sí, debemos hacer una advertencia: aún no se han inventado sus categorías de reemplazo. Pero Pizza, Birra, Faso podría ser un buen ejercicio de problematización de la colonialidad, si pensamos en ella desde la crítica poscolonial y desde la noción de «modernidades múltiples».

\section{PIZZA, BIRRA, FASO Y LA DESUSTANCIACIÓN DEL SUJETO}

Sujetos que deambulan por el Gran Buenos Aires sin rumbo. No tienen pasado. No pertenecen o están adscritos a ninguna clase social en los términos en que el materialismo histórico las entiende. Sin embargo, podemos decir que son marginales, pobres, delincuentes y disfuncionales a la comprensión sistémica de lo social - y a la "Ciudad Letrada» de la cual hablara Ángel Rama- que tiende a homogeneizar las naciones y a pensar en una totalidad donde todas las partes se subordinan a la totalidad. Pizza, Birra,

14 El autor estadounidense Fredric Jameson homogeniza toda la producción del «Nuevo Cine Latinoamericano» en torno al concepto de "alegorías nacionales", como si se tratase de una producción uniforme (124-26). La dimensión política se expresaría en forma de alegoría representada en el texto fílmico mediante la historia del destino personal de un sujeto que encarnaría «la problemática situación de la cultura del Tercer Mundo" (Stam, 328). Pero si bien muchas de las cintas pueden calificarse de alegóricas (en su función), tal categorización impide observar las diferencias de construcción y de producción de las películas. De alguna manera la categoría expropia a los cines nacionales de sus particulares contextos y, de paso, no nos permite comprender los imaginarios propios de relación con las modernidades. 
Faso $^{15}$, la primera película del cineasta uruguayo Israel Adrián Caetano nos sitúa en una metrópoli latinoamericana casi estallada, a fines de los años 90, en momentos en que la llamada «Crisis Asiática» ya empezaba a mostrar sus consecuencias sociales negativas que en la cinta se pueden observar con las tomas y paneos (movimientos de cámara de derecha a izquierda o al revés sobre el eje de la misma) con los que la cámara nos muestra las paredes con propaganda alusiva a movilizaciones de trabajadores y huelgas. En este contexto se mueven cinco jóvenes que forman una especie de pandilla, cuyos cabecillas son «el cordobés» y Pablo. Son ladrones de poca monta que actúan en muchas ocasiones con extrema violencia, pero también son capaces de exhibir gran ingenuidad en otras.

Desde el comienzo del filme hace aparición la marca de fábrica de Caetano, la inclusión de la «cumbia villera» como música central. Intercalados con los créditos, las tomas nos muestran el Buenos Aires cotidiano, mundano y moderno, con ruido, flujo y en plena actividad: autos circulando por las grandes avenidas, la policía y los famosos limpiaparabrisas como símbolo de una economía informal, como símbolo de unos procesos de modernización que han dejado a muchos excluidos del reparto de la «buena nueva» de la modernidad tardía en Argentina, probablemente extensible a muchas modernidades en otros países latinoamericanos ${ }^{16}$. Luego, la imagen de Pablo y «el cordobés» en un taxi conversando con su dueño, un delincuente «integrado", quien les provee de armas para asaltar a sus propios pasajeros. De algún modo éste será el derrotero de estos hampones: recibir órdenes, cometer asaltos menores como en la secuencia en la que simulan ser «cesantes» que van a buscar empleo, pero en realidad su pretensión era asaltar a algún incauto que estuviese en la fila. Paralelo a estos atracos, se exhibe su vida cotidiana caracterizada por tomar cerveza, comer pizzas y fumar marihuana frente al Obelisco e incluso dentro de él. Además queda tiempo para iniciar una relación amorosa entre el protagonista «el cordobés» y Roxana. Probablemente éste sea el único gesto de redención de la cinta. Pero se trata de individuos — no de sujetos, en el sentido de que no están integrados en la máquina social - cargados con un destino fatal, antihéroes y subalternizados por otros delincuentes. Por tanto la película debe terminar con la tragedia de la vida, la muerte del «cordobés» tras el asalto a una discotheque y su posterior huida, malherido por la policía, no sin antes entregarle el botín a su amada que lo esperaba en el embarcadero para huir a Uruguay e iniciar una nueva vida.

En el ámbito del lenguaje cinematográfico y las condiciones materiales de producción se trata de una película realizada con bajo presupuesto, con actores no profesionales

15 Pizza, birra, faso ha sido sindicada por la crítica de cine especializada como una de las primeras películas de lo que han llamado el «Nuevo cine argentino de los 90 ». Ciertamente en la historia del cine hecho en América Latina en varias oportunidades se ha decretado el surgimiento de lo nuevo y, como tantas otras, se ha hecho en función de lo anterior que se califica como "el viejo cine». ¿A qué se refieren los críticos cuando se refieren al «viejo cine»? A un tipo de cine sin pretensiones artísticas y no meramente comerciales que surge con el reinicio de la democracia argentina en 1983 y que hacia mediados de los noventa «se encuentra en decadencia económica, con dificultades en su producción y sobre todo en su llegada al público» (Cartoccio:4). ¿Qué características suponen los críticos que serían adjudicables al «viejo cine» en contraposición con el nuevo? Esta respuesta la da el investigador en cine argentino Eduardo Cartoccio: «A la sobreactuación de los actores estrellas del viejo cine, se contrapone la sobriedad de los no-actores del nuevo cine; al verbalismo, los diálogos medidos y el silencio; al simbolismo y la alegoría de las imágenes que pretender ser «concretas〉 y no remitir simbólica o alegóricamente a otras cosas» (5).

16 Sobre la denuncia de los aspectos negativos de la modernidad en sentido general, Marshall Berman dice: «Es irónico y contradictorio, polifónico y dialéctico, denunciar la vida moderna en nombre de los valores que la propia modernidad ha creado, esperar - a menudo contra toda esperanza- que las modernidades de mañana y pasado mañana curarán las heridas que destrozan a los hombres y las mujeres de hoy» (10). 
mezclados con otros que sí lo son ${ }^{17}$. Combina la ficción con el documental y los géneros (en este caso la comedia negra y el melodrama), al igual que Memorias del Subdesarrollo, utiliza una película que da la sensación óptica de una realidad borrosa y descolorida como la vida opaca de estos seres obtusos en una ciudad hostil y bajo una modernidad en crisis - como si esta realidad fuese irrepresentable de otra manera-que cuando han sido representados en el cine los ha mostrado bajo una matriz estereotípica y paternalista. Pero en ambos casos, de forma maniquea ${ }^{18}$.

Debemos señalar que este tipo de cine que exhibe lo marginal, los bordes sociales sin moralejas y realizado en los años 90 y en la primera década del siglo Xxi, se le ha llamado «Realismo Sucio» o «Cine de la Marginalidad». De acuerdo al crítico ecuatoriano Christian León, la marginalidad se representa como una «agencia virulenta que opera desde las entrañas de las instituciones culturales modernas» (9). En gran medida, estos discursos cinematográficos sobre individuos abyectos y marginales podrían entenderse como un desafío al orden y a las categorizaciones que establece la institucionalidad tradicional y que aparecen como el «lado oscuro de la modernidad» en Argentina. Además se trata del traspaso o la burla de los límites de adentro y de afuera de estas instituciones sociales. Eso sí, los delincuentes siempre operando en el ámbito de las tácticas de evasión institucional y nunca en el terreno de las estrategias formales de la sociedad. Por estas características Christian León se atreve a ensayar su tesis respecto al «Realismo Sucio»: existiría una correspondencia entre la labor de desmonte deconstructiva "presente en el texto fílmico y el pensamiento poscolonial, que define al sujeto subalterno desde su indecibilidad» (León, 10). No obstante, esta deconstrucción que el autor sugiere se despliega en películas como Pizza, Birra, Faso, no nos debe llevar a la apología del delito, ni tampoco a pensar que se trata de un tipo de cine que luego de poner en tensión las instituciones tradicionales de la modernidad, cuando amenaza la ciudad del orden, elabore nuevas categorías para pensar-nos. Exigencia que ni las Ciencias Sociales, ni las humanidades han logrado concretar hasta ahora, por lo demás. Se trata más bien, en nuestra opinión, de una operación analítica, que reconoce, problematiza y distingue posiciones, movimientos y espacios de acción de sujetos marginales — y sus desventuras citadinas-, evidenciando sus contradicciones vitales y las del sistema y que, por sobre todo, no permite siquiera imaginar un afuera de la propia representación, o incluso plantear su posibilidad. Representación, eso sí, que da cuenta de un tipo de malestar profundo por las condiciones

17 En relación con el lenguaje verbal y los diálogos en Pizza, birra, faso, se lee en el texto Historias extraordinarias. Nuevo cine argentino: «(..), los movimientos nerviosos de la cámara, el montaje frenético, el sonido ambiente reforzado por el murmullo de una emisora radial y una música que resultaba nueva para la tradición del cine argentino - la cumbia- decían que se estaba ante el comienzo de un cambio de paradigma. Cuando finaliza el prólogo y la película se enfoca en sus protagonistas, aparece una nueva sorpresa: el lenguaje. [...] Es común que los cines nacionales salgan de sus crisis de representación a través de una vuelta al realismo y el terremoto estético que representó Pizza para la Argentina no fue una excepción. Sin embargo, los espectadores no estaban preparados para el lenguaje de sus personajes: era imposible saber si era realista o impostado ya que ningún espectador de cine había escuchado hablar a nadie de esa manera. [...] Estéticamente fue un quiebre radical pero socialmente preanunció a los nuevos actores que inundarían las calles de la ciudad por los próximos años, aquellos desclasados y protodelincuentes a los que la burguesía argentina aprendería a temer» (Pena, 111).

18 Gustavo Noriega, director y crítico de una de las revistas de cine más importantes en Argentina, se refiere al tipo de representaciones sociales desplegadas por Caetano en Pizza, birra, faso de esta manera: «No se trataba del habitual paternalismo del realizador de ideales progresistas sino de que, efectivamente, Caetano tenía más que ver en su vida cotidiana con los personajes marginados que retrataba que con el público que veía su ópera prima y con los críticos que la veneraban» (112). 
de vida en una ciudad, la de Buenos Aires, asediada por las consecuencias negativas de una versión de la modernidad de fin de siglo, caracterizada por las consecuencias sociales negativas que ha dejado (y deja) el modelo económico neoliberal.

Pero el cine por medio de todos sus artificios puede sintetizar y focalizar los puntos conflictivos de nuestro presente o, en otros casos, narrar lo indecible, lo que tradicionalmente ha quedado por fuera de la sociedad del orden: la marginalidad. Sobre la categoría marginalidad dice León:

A finales de los sesenta surge el concepto de marginalidad en L.A. fruto de los debates sobre la modernización. Desde visiones funcionalistas se designa como población marginal a un sector sin empleo estable, necesitado de la gestión del Estado para su inserción. (...) En los setenta, en las comprensiones marxistas, surge la categoría «masa marginal» que corresponde al sobrante de fuerza de trabajo en relación a las necesidades del capital (11).

Mientras en una matriz se impulsó la Revolución y la transformación social, como en Memorias del Subdesarrollo; en la otra, se confinó al individuo marginal a su esencialización, afianzándose las lógicas mismas de la colonialidad. León plantea, por ello, una redefinición del concepto marginalidad:

[...] redefinimos la marginalidad como ese exterior constitutivo de la sociedad que, como lo ha mostrado Derrida, obra necesariamente desde el interior. [...] El cine de la marginalidad (huérfanos, los olvidados, los desempleados) cuyo centro son los individuos disfuncionales cuya realidad opera en los bordes de la racionalidad productiva de la modernidad (13).

Desde esta perspectiva, la episteme o las epistemes en juego implican entender a la marginalidad y a una de sus expresiones, la delincuencia y el sujeto delincuente como interioridad difícil de emplazar en un terreno reconocible y seguro. El espacio heterotópico se entrecruza con el espacio tópico (Foucault, 1984) y, con ello, reaparece la noción de heterogeneidad social. En consecuencia, la totalidad sólo es pensable si se acepta que la sociedad, la nación, está conformada por fragmentos, por variabilidades articuladas, como advertía Quijano (Castro-Gómez y Grosfoguel, 2007), por un eje ordenador. Los delincuentes «están entre nosotros» a pesar de que nos esforzamos por «sacarlos de circulación», ubicándolos en cárceles, invisibilizándolos socialmente. Quizás, por esta razón Caetano despliega y arroja al mundo a los delincuentes y los ubica en un espacio abierto: la vida cotidiana de la Ciudad de Buenos Aires ${ }^{19}$.

¿Cómo representar esta marginalidad interior? Evitando las construcciones y las narraciones costumbristas y naturalistas. Ya no es posible sostener la existencia de identidades esenciales, psicologizantes o metafísicas, como lo hizo Memorias del Subdesarrollo al intentar responder a la colonialidad: lo cierto es que ahora estamos en presencia de individuos nómades, cuya mejor metáfora la entrega Caetano al hacerlos deambular por la ciudad, sin proyecto, ni horizonte transformador, como lo dictaminan los relatos positivos sobre la modernidad europea y estadounidense y sobre los procesos de modernización sugeridos para América Latina en los 50 y 60 del siglo pasado (procesos que advertían que si se imitaban ciertas estrategias de los países desarrollados, mágicamente

\footnotetext{
Así se refiere el crítico argentino Gustavo Noriega a la operación cinematográfica realizada por Caetano al disponer, en el medio de la ciudad de Buenos Aires, a sujetos delincuentes amenazando la "paz» social: «Estéticamente fue un quiebre radical pero socialmente preanunció a los nuevos actores que inundarían las calles de la ciudad por los próximos años, aquellos desclasados y protodelincuentes a los que la burguesía argentina aprendería a temer» (Pena, 111).
} 
convertirían a las naciones latinoamericanas en naciones modernas). En otras palabras, son la otra cara de la modernidad tardía, la región interior y oscura de las instituciones. La derrota de la constitución del sujeto monolítico, pues los representados en Pizza, Birra, Faso, no pueden hablar, por lo menos en voz alta y en presencia de lo oficial. Se trata, más bien, de un juego de posiciones y tácticas que amenazan de tarde en tarde la ciudad ordenada y el orden del discurso de una modernidad que aspira a la fijación de certezas pero que, paradójicamente, en su proyecto siempre se le cuelan haciendo visibles sus contradicciones, su lado oscuro e indecible.

Finalmente, en Pizza, Birra, Faso y en Memorias del Subdesarrollo se han podido apreciar dos modalidades históricas de respuestas a la colonialidad y dos maneras de «imaginar» la modernidad: en la primera, una posibilidad de desmonte y auscultación de los límites de lo social, de sus categorizaciones; en la segunda, una perspectiva que opera en el interior de sus gramáticas y nos las descompone, no las deconstruye. Pese a esto, los usos del lenguaje cinematográfico son similares: como ya hemos dicho, el empleo de una fotografía documental, la escasa utilización de música que puntúe las secuencia de imágenes —aunque en Memorias del Subdesarrollo la música sea más usual—, la utilización de una cámara que capte las pulsiones de la vida por medio de lo que en cine se llaman los puntos muertos (tomas donde aparentemente no ocurre nada) de la narración. Todos estos recursos al servicio de un afán verista, al servicio de constituir a un espectador observador de la realidad, mejor dicho, de las realidades, pues se trata de cintas construidas en distintos entornos nacionales, sociopolíticos y culturales, de unas modernidades latinoamericanas siempre actualizables, siempre contradictorias. Se trata de dos modos distintos de «imaginar» lo colectivo y su expresión identitaria más eficaz, la nación. Mientras en la película de Gutiérrez Alea, se despliega y se aspira a la «educación» y a la modernización de los sujetos miembros del pueblo en pos de alcanzar la forma histórica de la «civilización», en la de Caetano la «nación» ya no puede reconocerse como aquella narración que pudiese aglutinar y cohesionar la totalidad social. Los delincuentes están entre nosotros, amenazando la tranquilidad de la nación ordenada como si la diferencia ya no pudiese delimitarse para conjurar la amenaza de aquellos sujetos peligrosos y marginales ${ }^{20}$. Por esta razón, Pizza, birra, faso no tiene moraleja: no nos permite ver e imaginar otra comunidad y pareciese ser ésta la tragedia de nuestros problemas contemporáneos en la América Latina de la tardomodernidad.

«La colonialidad nos piensa, la poscolonialidad piensa en el borde», sería la conclusión provisoria, pero queda el camino más complejo: reflexionar desde la poscolonialidad y desde otra modernidad instalando nuevas epistemes, nuevos conceptos y nuevas categorizaciones para nombrar la realidad y para saber de qué materiales y de qué densidades se compone en América Latina. Tal vez desde las imágenes podamos pensar de otro modo, pensar e imaginar el presente y el futuro de las naciones latinoamericanas desde sus propios lugares de enunciación.

20 Lo que estaría en crisis sería la idea nación que Benedict Anderson define de esta forma: «(...) una comunidad política imaginada como inherentemente limitada y soberana» (23). 


\section{REFERENCIAS}

Brunner, Joaquín. «Modernidad». Términos críticos de sociología de la cultura. Altamirano, Carlos. Buenos Aires: Paidós, 2002. Medio impreso.

Brunner, José Joaquín. Modernidad: Centro y Periferia. Santiago de Chile: Centro de Estudios Públicos (CEP) 83, Invierno de 2001. Medio impreso.

Casetti, Francesco. Teorías del cine. Madrid: Cátedra, 1993. CASETTI

Castro-Gómez, Santiago y R. Grosfoguel. El giro decolonial. Bogotá: Pontificia Universidad Javeriana-Instituto Pensar, 2007. Medio impreso.

Castro-Gómez, Santiago. La Poscolonialidad explicada a los niños. Bogotá: Editorial Universidad de Cauca/Instituto Pensar. Universidad Javeriana, 2005. Medio impreso.

Deleuze, Gilles: «¿Qué es un dispositivo?» Michel Foucault, Filósofo. Barcelona: Gedisa, 1990. Medio impreso.

García Canclini, Néstor. Culturas híbridas: estrategias para entrar y salir de la modernidad. Buenos Aires, Paidós, 2001. Medio impreso.

Girola, Lidia. Imaginarios socioculturales de la modernidad. Aportaciones recientes y dimensiones del análisis para la construcción de una agenda de investigación. Revista Sociológica 64, año 22 (2007). Medio impreso.

Gutiérrez Alea, Tomás. La dialéctica del espectador. La Habana: Ediciones Unión, 1978. Medio impreso.

Jamesom, Fredric. La estética geopolítica. Barcelona. Paidós, 1995. Medio impreso.

King, John. El carrete mágico. Una historia del cine latinoamericano. Bogotá: Editores Tercer Mundo, 1994. Medio impreso.

Larraín, Jorge. La trayectoria latinoamericana a la modernidad. Centro de Estudios Públicos 66 (1997). Medio impreso.

- ¿América Latina Moderna? Globalización e identidad. Santiago de Chile: LOM Ediciones, 2005. Medio impreso.

León, Christian. El cine de la marginalidad. Realismo sucio y violencia urbana. Quito: Universidad Andina Simón Bolívar-Ediciones Abya-Yala, 2005. Medio impreso

Marín, Álvaro y Juan Jesús Morales. Modernidad y modernización en América Latina: una aventura inacabada. Revista Nómadas 26 (2010). Medio impreso.

Martín-Barbero, Jesús. De los medios a las mediaciones. Comunicación, cultura y hegemonía. Bogotá: Convenio Andrés Bello-Gustavo Gili, 1998. Medio impreso.

Mignolo, Walter. "Colonialidad Global, Capitalismos y Hegemonía Epistémica». Culturas Imperiales, Experiencia y Representación en América, Asia y África. Viterbo Editora: Rosario, 2005. Medio impreso.

Quijano, Aníbal: "Colonialidad del poder y clasificación social». El giro decolonial. Bogotá: Pontificia Universidad Javeriana-Instituto Pensar, 2007. 93-126. Medio impreso.

Quiroz, Héctor. El malestar por la ciudad contemporánea a través del cine. Tesina para obtener el master en Historia, arte, arquitectura y ciudad, Universidad de Barcelona, 2001. Medio impreso.

Ortega, Víctor. "Crítica social y géneros en el cine de Adrián Caetano». Documentos de Trabajo del CECOM 5 (2008). Sitio Web.

Ortiz, Renato. Modernidad y espacio. Benjamin en París. Bogotá: Editorial Norma, 2000. Medio impreso. 
I 40

Ossandón, Carlos y Eduardo Santa Cruz. El estallido de las formas. Santiago de Chile: LOM-Arcis, 2005. Medio impreso.

Pena, Jaime. Historias extraordinarias. «Israel Adrían Caetano/Adrián Israel Caetano» Buenos Aires: T y B Editores, 2009. Cap. Medio impreso.

Restrepo, Eduardo. «Antropología y colonialidad». El giro decolonial. Bogotá: Pontificia Universidad Javeriana-Instituto Pensar, 2007. 289-304. Medio impreso.

Rufinelli, Jorge. América Latina en 130 películas. Santiago de Chile: Uqbar Editores, 2010. Medio impreso.

Salinas, Claudio y Hans E. Stange. «Políticas en Imágenes. Una re-visión del documental Venceremos». S.E., 2010. Medio impreso.

Stam, Robert. Teorías del cine. Barcelona: Paidós, 2001. Medio impreso.

Thompson, John B. Los media y la modernidad. Una teoría de los medios de comunicación. Buenos Aires: Paidós, 1998. Medio impreso.

Williams, Raymond. Marxismo y Literatura. Barcelona: Península, 1980. Medio impreso.

. Historia de la Comunicación. Barcelona: Bosch Casa Editorial, 1992. Medio impreso.

. Sociología de la cultura. Barcelona: Paidós, 1994. Medio impreso.

Zunzunegui, Santos. Pensar la imagen. Madrid: Universidad del país Vasco-Cátedra. Col. Signo e Imagen, 2005. Medio impreso.

\section{PELÍCULAS}

Memorias del Subdesarrollo. Tomás Gutiérrez Alea. ICAIC, Cuba, 1968. ICAIC, Fílmico.

Pizza, Birra, Faso. Israel Adrián Caetano y Bruno Stagnaro. Alta Films S.A., Argentina, 1999. Palo y la Bolsa Cine, Fílmico. 